\title{
BUEN VIVIR: CRÍTICAS Y BALANCES DE UN PARADIGMA SOCIAL EN CONSTRUCCIÓN
}

\author{
BUEN VIVIR (LIVING WELL): REVIEWING THE BALANCE SHEET \\ OF A SOCIAL PARADIGM UNDER CONSTRUCTION
}

\author{
Kepler Ribadeneira Aroca*
}

\begin{abstract}
El Buen Vivir es un discurso debilitado en Ecuador, pese a que forma parte de la institucionalidad del país, sin embargo genera expectativa entre la intelectualidad global debido a que contribuye a los debates para construir una nueva epistemología del Sur. Este artículo tiene como propósito mostrar las paradojas del paradigma en construcción, para ello analiza su entramado conceptual, los usos y procesos de resignificación a tono con las decisiones de los gobiernos de turno y los desafíos que supone su implementación para las sociedades latinoamericanas, en particular la ecuatoriana. Se concluye que implementarlo requiere del diseño de políticas públicas creativas y coherentes con el andamiaje constitucional y de un diálogo intercultural y democrático que permita superar la matriz de exclusión, alienación e insostenibilidad.
\end{abstract}

Palabras claves: Buen Vivir, comunidad, desarrollo, discursos del Sur, Ecuador, ambientalismo.

The discourse of Buen Vivir (Living Well) has lost force in Ecuador, even though it is institutionalized at the national level. Nevertheless, it has raised expectation in intellectual circles at a global level, since it contributes to the debates surrounding the construction of a new epistemology of the South. This article seeks to show the paradoxes inherent in this emerging paradigm, and to that end analyses its conceptual framework, the uses and processes of reinterpretation that accompany the decisions of each new government, and the challenges implied by its implementation for the societies of Latin America, and in particular of that of Ecuador. It is concluded that implementation requires the design of creative public policies coherent with constitutional structure and dialogue both intercultural and democratic that would allow us to rise above the pattern of exclusion, alienation and unsustainability.

Key words: Buen Vivir (Living Well), community, development, discourses of the South, Ecuador, environmentalism.

\section{Buen Vivir o Sumak Kawsay}

El preámbulo de la Constitución de la República del Ecuador señala que los ecuatorianos deciden construir "una nueva forma de convivencia ciudadana, en diversidad y armonía con la naturaleza para alcanzar el Buen Vivir, el Sumak Kawsay" (Asamblea Nacional Constituyente 2008), una propuesta holística, por tanto compleja de aplicar, que se cimienta en la identidad multicultural del pueblo ecuatoriano y de otras corrientes civilizatorias globales, incluida la occidental. Los dos sintagmas, uno en español y otro en kichwa, se refieren a la construcción de un nuevo paradigma como respuesta al modelo de desarrollo antropocéntrico fundamentado en el mercado (Caria y Domínguez, 2016) y es el referente del sur para los debates frente al decrecimiento que propone la centralidad (Beling et al., 2018).

Buen Vivir y Sumak Kawsay están relacionados con la lucha y resistencia de los pueblos indígenas del continente, quienes, en el caso de Ecuador, irrumpen con fuerza en la política a inicios de la década de los 90 del siglo XX, aunque su disputa de larga data ya había generado hace 20 años las bases conceptuales de su visión del cambio en las relaciones de poder (Altmann, 2013).

En 1997, al calor del debate de reforma de la Constitución ecuatoriana, la Confederación de Nacionalidades Indígenas del Ecuador (Conaie) presenta su proyecto político en el que, si bien no menciona al Sumak Kawsay, realiza un amplio planteamiento para la reforma estructural del Estado al que califica de uninacional hegemónico, * Universidad Técnica de Manabí. Facultad de Humanística y Ciencias Sociales. Portoviejo, Manabí, Ecuador.
Correo electrónico: kribadeneira@utm.edu.ec. Apartado postal: 82. 
excluyente, antidemocrático y represivo. Sobre esa base, remarca la necesidad de instaurar un Estado plurinacional, pluricultural y plurilingüe (Conaie, 1997: 218). En su proyecto político, la organización indígena da amplias señales de los principios ideológicos que dan sustento a su propuesta y a la vida misma de la organización, por lo que llama la atención la abstracción que se hace en relación con un humanismo integral que "defiende, respeta y afirma los derechos de todas las vidas: de los seres humanos y de la naturaleza; como sustento de la espiritualidad, religiosidad, pensamiento y conocimiento de los pueblos y nacionalidades indígenas" (221).

Alberto Acosta, el expresidente de la Asamblea Constituyente ecuatoriana de 2008, afirma que el paradigma del Buen Vivir "viene del mundo indígena" y reconoce que uno de los actores de este proceso es la Conaie, por lo que sus postulados tienen que ser considerados como "eje fundamental de toda esta discusión" (Fernández, Pardo y Salamanca, 2014). También destaca los aportes de ILDIS (Instituto Latinoamericano de Investigaciones Sociales) que juntó a intelectuales para debatir nuevos modelos de construcción social, alternativos al neoliberalismo $\mathrm{y}$ al desarrollismo.

Se ha planteado que Buen Vivir y Sumak Kawsay son la traducción literal el uno del otro, pero no lo es, tanto así que la traducción al español o al inglés de Sumak Kawsay es prácticamente imposible a riesgo de que pierda su valor semántico (Belotti, 2014; Barranquero-Carretero \& Sáez-Baeza, 2015). Incluso para Buen Vivir se encuentran traducciones en inglés como Living Well, Good Life o Good Living. En publicaciones en lenguas distintas al español, los autores prefieren dejarlo como Buen Vivir. Semánticamente, como veremos más adelante, ambas frases (Buen Vivir y Sumak Kawsay) presentan diferencias irreconciliables.

En la búsqueda de una traducción para el Sumak Kawsay, García (2014) cita a Huanacuni quien señala que sumak significa "plenitud, sublime, excelente, magnífico, hermoso (a), superior, integral, simbiótico y holístico", mientras que kawsay, es "vida, ser-estando, estar-siendo". Se trata de un concepto nacido en el Abya Yala ${ }^{1}$ y todo lo que ha significado la lucha de los pueblos originarios contra la exclusión y el despojo que trajo consigo el colonialismo, por tanto en términos ideológicos implica "soberanía y dignidad nacional, apertura a nuevas formas de vida, la recuperación del derecho de relación con la madre tierra y la sustitución de la acumulación ilimitada individual por la recuperación integral del equilibrio y la armonía con la naturaleza" (Huanacuni, 2010: 7).

Larrea Mandonado (2012: 28) expresa que el Sumak Kawsay es una propuesta dotada de sentidos que se ata a los pueblos y naciones originarios del Ecuador, en cuya cosmovisión el futuro no existe porque importa el pasado, los ancestros, los ritos y costumbres, el anciano que dice cómo debe ser la relación de las personas con sus semejantes y la naturaleza. También tiene relevancia el componente de comunidad que refuerza la participación porque en el seno de los colectivos originarios de las regiones andina y amazónica se habla del nosotros, no de un sujeto individual característico del canon occidental.

Cubillo Guevara e Hidalgo Capitán (2015) estiman que el término Sumak Kawsay fue escrito por primera vez como modelo de vida alternativo al desarrollo en el Plan Amazanga de la Organización de Pueblos Indígenas de Pastaza, una de las provincias amazónicas de Ecuador. Luego vendrá, remarcan, un proceso para darle contenido. Estos mismos autores expresan que Carlos Viteri Gualinga, del pueblo amazónico Sarayacu, es el primer intelectual indígena que escribe de la relación entre el Sumak Kawsay y Buen Vivir. Al respecto, este líder indígena reflexiona en los siguientes términos:

\begin{abstract}
Mas existe una visión holística a cerca de lo que debe ser el objetivo o la misión de todo esfuerzo humano, que consiste en buscar y crear las condiciones materiales y espirituales para construir y mantener el 'buen vivir'; que se define también como 'vida armónica', que en idiomas como el runa shimi (qichwa) se define como el alli káusai o súmac káusai (Viteri Gualinga, 2002).
\end{abstract}

Oviedo (2012) anota que una traducción más acorde al Sumak Kawsay es establecer una vida en armonía, equilibrio y concertación, lo que además implica la conciliación, el aporte mutuo, no la superposición como lo plantea el Buen Vivir. Al referirse a "buen" observa que con el solo hecho 
de calificar algo como bueno o malo, se está frente a una construcción occidental en que las relaciones son verticales, no horizontales, lo que supone un Norte y un Sur, los de arriba y los de abajo, los desarrollados y los no desarrollados, los del centro y los de la periferia.

Los pensadores indígenas critican la conceptualización que ha dado al Buen Vivir la intelectualidad de izquierdas vinculada al gobierno del expresidente de Ecuador Rafael Correa Delgado (Oviedo, 2012). La cuestionan porque a su entender la desligan de la cosmovisión indígena al relacionarla con el planteamiento aristotélico para alcanzar la felicidad o el florecimiento humano (Bretón, 2013; Manosalvas, 2014) desde puntos de vista antropocéntricos. En el mismo sentido Atawallpa Oviedo agrega: "Se trata de un paradigma alternativo, diferente a los paradigmas de Occidente con sus líneas de izquierda y derecha, guardando una concordancia con las leyes del cosmos. El propósito es seguir el modelo de la vida de la naturaleza" (Oviedo, 2012).

Uno de los motivos por los que la definición de Buen Vivir confronta se debe a que es un concepto abierto, todavía en permanente resignificación. Villalba (2013) propone entender el concepto desde dos enfoques: uno inherente a la cosmovisión indígena y otro mestizo de contexto urbano donde los modernos postulados occidentales son abiertamente aceptados. Al respecto, Cubillo Guevara, Hidalgo Capitán y García Álvarez (2016), identifican los aportes de tres corrientes en el proceso del Buen Vivir: la indigenista, la socialista o ecomarxista y la posdesarrollista. Alberto Acosta las rechaza al señalar que el Buen Vivir "es un concepto plural (mejor sería hablar de "buenos vivires" o "buenos convivires") (Acosta, 2013), por tanto "sostener que el Buen Vivir, por definición es desarrollista, y que el Sumak Kawsay, en consecuencia, es indígena, es una simplificación que no contribuye al debate" y "recluiría las propuestas indígenas en un mundo estrecho y se minimizarían sus enormes potencialidades derivadas para librar una batalla conceptual y política orientada a superar la modernidad" (Acosta, 2015).

Por otra parte, Gudynas (2011) anota que deben observarse al menos tres aspectos para formalizar un concepto respecto del Buen Vivir: la concepción que tenemos del desarrollo; las nociones de crecimiento económico y el consumo superadas por una nueva forma de entender el mundo en que la calidad de vida incluye a la naturaleza, y la definición de políticas públicas alternativas a la cuestionada matriz de progreso. Insiste que puede ser entendido como "una plataforma donde se encuentran múltiples ontologías que se construirá desde la práctica de una interculturalidad que mira al mundo futuro para construir alternativas de desarrollo" (Gudynas, 2011). En este sentido, Caria y Domínguez manifiestan que sus pilares podrían resumirse en los siguientes: harmony with Nature, respect for the values and principles of indigenous peoples, satisfaction of basic needs, social justice and equality as responsibilities of the state, and democracy ${ }^{2}$ (Caria y Domínguez, 2016).

Philipp Altmann (2013) y Javier Medina (2011) aportan que el concepto fue inicialmente desarrollado por la intelectualidad indígena boliviana en el contexto del Diálogo Nacional 2000 que se llevó a cabo en Bolivia con el impulso de la agencia de Cooperación Técnica Alemana (GTZ). Se lo definió como "vivir austeramente en armonía y equilibrio consigo mismo, con la comunidad y con el cosmos" (GTZ, 2002: 24, en Altmann, 2013). Más recientemente Cubillo Guevara et al. (2016) lo redujeron a una "forma de vida en armonía con uno mismo, con la sociedad y con la naturaleza".

\section{Ajustes semánticos al paradigma}

En un primer trabajo de Cubillo Guevara et al. (2016), Hidalgo-Capitán y Cubillo-Guevara (2017) remarcan que las tres concepciones del Buen Vivir (la indigenista, la estatista y la postdesarrollista) han fluido juntas en los procesos teóricos y prácticos de la administración del Estado en Ecuador (lo mismo que en Bolivia). Esta interpretación coincide con los ajustes teóricos que Senplades, la Secretaría Nacional de Planificación y Desarrollo del Ecuador, realizó a los significados e implicaciones del paradigma. Esta institución lideró procesos inéditos de organización del Estado, los que se expresaron en sucesivos planes nacionales de desarrollo con base en la Constitución que incorpora el Buen Vivir. En su primer Plan Nacional del Buen Vivir (2009) Senplades enfoca la visión que en ese entonces el gobierno del expresidente Correa Delgado tenía de esta propuesta. El organismo sostiene que la 
idea del desarrollo es inexistente en la cosmovisión de los pueblos originarios y agrega:

La comunidad cobija, protege, demanda y es parte de nosotros (...). De ahí que el ser humano sea una pieza de este todo que no puede ser entendido en sus partes. La totalidad se expresa en cada ser y cada ser en la totalidad. «El universo es permanente, siempre ha existido y existirá; nace y muere dentro de sí mismo y solo el tiempo lo cambia» (pensamiento kichwa). De ahí que hacer daño a la naturaleza es hacernos daño a nosotros mismos (Senplades, 2009: p. 32).

La misma Senplades ${ }^{4}$, sin embargo, en su segundo Plan Nacional del Buen Vivir (2013), abre un poco más la diversidad en la fundamentación del paradigma al anotar que se nutre no solo de los saberes de los pueblos originarios andinos, sino también de otras culturas alrededor del mundo y enfatiza que "en la sabiduría ancestral común a los pueblos de la Tierra, el calificativo bueno de esta aspiración abarca no solo la definición de agradable y hermoso, sino la idea ética de lo bueno" (Senplades, 2013: 23). Y luego subraya:

El debate alrededor del Sumak Kawsay ha rebasado las fronteras ecuatorianas y latinoamericanas, ha impulsado la reflexión política y académica y ha recogido los aportes de movimientos sociales, académicos, líderes políticos y gestores de política pública. Se trata de una noción en permanente construcción (23).

La declaración de principios para lograr el Buen Vivir entre los planes nacionales de 2009 y 2013 muestra esos matices discursivos, especialmente en el ámbito político, de hecho, Senplades (2013: 24) expresa que "el horizonte político de la Revolución Ciudadana es el Socialismo del Sumak Kawsay" (Tabla 1), una abstracción respeto de la que René Ramírez, uno de los ideólogos del gobierno de Correa Delgado, también llamó "biosocialismo (igualitarismo) republicano" (Ramírez, 2012: 22-35; Ramírez, 2014) que tiene como base los derechos de las personas y de la naturaleza consagrados en la Constitución de 2008.
En el caso del Plan Nacional de Desarrollo (PND) del gobierno de Lenin Moreno (años 2017-2021) no hay una declaración expresa de principios para entender la corriente ideológica que seguirá la planificación del Estado. Se da por descontado que se desprende de la Constitución del Buen Vivir, aunque se recalca el énfasis en desmarcarse de los anteriores planes de desarrollo al señalar que el documento está "alejado de la visión estática y rígida de la planificación tradicional (anterior)" (Senplades, 2017: 36).

El Buen Vivir ha sido resignificado en el discurso del poder así como se observa en los documentos base de la planificación del Estado ecuatoriano. Por ello, desde la intelectualidad se comienza a ver con pesimismo una posible consolidación del paradigma a la luz de las decisiones del mismo gobierno que lo promovió, el de Rafael Correa Delgado, y de la administración de Lenin Moreno Garcés, nacida en la misma corriente de lo que se denominó "Revolución Ciudadana"3. Incluso, el presidente Moreno Garcés se ha acercado a organismos multilaterales de crédito con el propósito de fondear las arcas fiscales, algo que es impulsado por la derecha pero criticado por los movimientos sociales que promovieron a ambos líderes como binomio presidencial en 2006. Jhon Cajas Guajarro enfatiza que en el segundo año de mandato de Moreno Garcés, iniciado en 2017, "el panorama se aclaró y el neoliberalismo clásico volvió a asomar, aunque este retorno ya se venía sembrando en los últimos años de Rafael Correa" (Guajarro, 2018).

Las paradojas del discurso se evidencian en las decisiones prácticas de los gobernantes, contradictorias con los principios del Buen Vivir pese a que el paradigma se articula en una Constitución garantista en materia de derechos humanos y en la protección de la naturaleza a la que también dota de derechos (Lalander y Merimaa, 2018). Un ejemplo de las distancias entre los discursos y las prácticas se encuentra en un estudio de Turra Díaz, Lagos Pando y Valdés Vera (2018) respecto de la propuesta curricular escolar para las ciencias sociales en la región (8 países). Aunque hay avances en Ecuador y especialmente en Bolivia, hallaron en todos los casos "la persistencia de un relato histórico anclado en una comprensión occidental del mundo", lo que evidentemente trabará procesos de aprendizaje con perspectiva intercultural. 
Tabla 1. Principios del Buen Vivir en la planificación del Estado ecuatoriano para los períodos 2009-2013, 2013-2017, 2017-2021.

\begin{tabular}{|c|c|c|}
\hline PNBV 2009-2013 & PNBV 2013-2017 & PND 2017-2021 \\
\hline $\begin{array}{l}\text { - La unidad en la diversidad } \\
\text { - Un ser humano que desea vivir en } \\
\text { sociedad } \\
\text { - La igualdad, la integración y la } \\
\text { cohesión social } \\
\text { - El cumplimiento de derechos } \\
\text { universales y la potenciación de las } \\
\text { capacidades humanas } \\
\text { - Una relación armónica con la } \\
\text { naturaleza } \\
\text { - Una convivencia solidaria, fraterna y } \\
\text { cooperativa } \\
\text { - Un trabajo y un ocio liberadores } \\
\text { - La reconstrucción de lo público } \\
\text { - Una democracia representativa, } \\
\text { deliberativa y participativa } \\
\text { - Un Estado democrático, pluralista y } \\
\text { laico }\end{array}$ & $\begin{array}{l}\text { - Sociedad radicalmente justa } \\
\text { - Sociedad con trabajo liberador y } \\
\text { tiempo creativo } \\
\text { - Sociedad de plenas capacidades, } \\
\text { emancipación y autonomía } \\
\text { - Sociedad solidaria } \\
\text { - Sociedad igualitaria y equitativa } \\
\text { - Sociedad corresponsable y propositiva } \\
\text { - Sociedad en armonía con la naturaleza } \\
\text { - Sociedad de excelencia } \\
\text { - Sociedad pluralista, participativa y } \\
\text { - Putodeterminada } \\
\text { - Srimacía de los bienes superiores } \\
\text { - Estado democrático, plurinacional y } \\
\text { - Faico } \\
\text { Fortalecimiento de la sociedad }\end{array}$ & $\begin{array}{l}\text { - Se omite una declaración de } \\
\text { principios, a diferencia de los } \\
\text { planes de desarrollo anteriores, } \\
\text { aunque se plantean tres ejes en } \\
\text { la gestión del plan, todos estos } \\
\text { atados al Buen Vivir: la garantía } \\
\text { de derechos a lo largo del ciclo } \\
\text { de vida, una economía al servicio } \\
\text { de la sociedad, y la participación } \\
\text { de la sociedad y la gestión estatal } \\
\text { para el cumplimiento de objetivos } \\
\text { nacionales. Son transversales la } \\
\text { sustentabilidad y el desarrollo } \\
\text { territorial. }\end{array}$ \\
\hline
\end{tabular}

Tomado de Senplades 2009, 2013, 2017.

Vanhulst, y Beling (2014) anotan que "la fluidez de sus contornos semánticos hace que el Buen Vivir sea vulnerable a la explotación o cooptación instrumental con el propósito de legitimar las decisiones políticas y las configuraciones socioeconómicas claramente ajenas a este espíritu". El escenario ambiental choca con el económico y social en contextos de amplios debates con ideas irreconciliables entre diferentes puntos de vista anclados al ambientalismo-ecologismo; antropocentrismo-postantropocentrismo; derechos culturales / étnicos-derechos socioeconómicos.

Salamea Córdova (2014) apunta al debilitamiento sistemático del tejido asociativo, habiendo asistido el pueblo ecuatoriano a "una revolución sin ciudadanía". Para ejemplificarlo Lindsay Shade (2015), al referirse a las luchas comunitarias contra la minería a cielo abierto, habla de que Ecuador tiene "zonas de sacrificio" donde se persigue a los activistas y dirigentes sociales. En ese contexto Villalba-Eguiluz y Etxano (2016) ponen en relieve los debates respecto de la incompatibilidad del Buen Vivir con el modelo neoextractivista (Hollender, 2012).

Al comentar el estilo de gobierno del expresidente Correa Delgado, De Sousa Santos (2014) lo encasilla como un "capitalismo del siglo XXI", debido a que no se superó la fase extractivista de los recursos naturales, más bien fortalecida en Ecuador con el precedente de la cancelada Iniciativa Yasuní. El intelectual agrega que el ex-Presidente fue el "gran modernizador del capitalismo ecuatoriano", sin embargo el modelo de crecimiento pese a estar anclado en el papel al ethos del Buen Vivir no logró complicar al comercio ni modificar el patrón de acumulación y mantuvo sus rasgos de primario exportador al vaivén de los precios de los commodities, con efectos en las finanzas públicas (Ugarchete, 2018).

Walsh (2010) se pregunta si el Buen Vivir es otra herramienta discursiva, un término cooptado, funcional al Estado y sus estructuras y con escasa importancia para una verdadera transformación intercultural, interepistémica y plurinacional. Bretón en cambio habla en pasado y señala que se trató "de un paradigma que trataba de llevar las mieles del desarrollo a los marginados rurales sin necesidad de una transformación radical de las estructuras de poder" (Bretón, 2013). De igual manera Caria y Domínguez (2016) remarcan que el socialismo del Sumak Kawsay es una "falsa conciencia" que oculta la realidad y que una vez alcanzado al estatus de una "ideología dominante" se vuelve "contradictorio e intolerante". Con estos últimos coinciden Acosta y Guajarro (2018) 
al afirmar que toda la propaganda estatal durante los años de mandato de Correa Delgado, "pueden ocultar la realidad de que toda una década se desperdició".

\section{Un discurso en permanente construcción}

Pese a las contradicciones evidentes, se observa con expectativa los desafíos que supone la implementación del Buen Vivir en entornos en que el Estado puede recuperar su papel regulador frente al mercado. En un análisis de las políticas redistributivas, a partir de los debates teóricos y prácticos del paradigma frente al (neo) extractivismo. Villalba-Eguiluz y Etxano (2016) enfatizan que hasta 2014 encontraron en Ecuador "mejoras en el gasto social y en la reducción de la pobreza y la desigualdad de ingresos", sin embargo esos avances se revierten debido a la sucesión de temas pendientes en una diversidad de aspectos, entre ellos la reforma fiscal.

Satrustegui (2013), Belotti (2014) y De la Cuadra (2015) reivindican el interés que despierta el paradigma entre los académicos y lo relacionan con la noción del Decrecimiento (Francia) y el Bien Común (Italia) al fundamentarse las tres corrientes en el rechazo a "la idea convencional del bienestar basada en el papel central del crecimiento económico" (Satrustegui, 2013). Entonces, caben nuevas interpretaciones y profundos debates salidos desde el sur, en específico de Latinoamérica.

Vanhulst (2015) destaca como el Buen Vivir se ha alimentado del debate académico a escala mundial y lo grafica con las búsquedas en Google Scholar, las que crecieron exponencialmente a partir de 2007 cuando inició el debate de cara a los procesos constituyentes de Ecuador y Bolivia. Este autor ve dos corrientes, una más radical que defiende la visión desde el Sumak Kawsay y otra más moderada, dialógica, que incorpora discursos postdesarrollistas, lo que a su vez abre nuevas posibilidades para abrirse paso entre los discursos conservadores.

Debe entenderse que la construcción del Buen Vivir es un trabajo en progreso que se alimenta de la cultura de los pueblos y nacionalidades originarias andino y amazónico, a la vez que incorpora principios de otras culturas, occidentales entre ellas (marxismo, feminismo, ecologismo, humanismo, cooperativismo), en la búsqueda de respuestas a "viejos problemas para remontar la pobreza o conquistar la igualdad" (Gudynas y Acosta, 2011; Acosta, 2010). Como lo enfatiza Margolis Schweber (2017) al relacionar sus significados con otras formas de pensar orientales y occidentales: "es un mosaico filosófico que busca una nueva comunidad más consciente y decidida a seguir prácticas de vida que aclaran la vida misma".

Las propuestas del Buen Vivir (Constitución de Ecuador) y del Vivir Bien (Constitución de Bolivia) puede verse como el resultado de la larga data de luchas populares ${ }^{5}$ (Acosta, 2015; Carvalho y Friggeri, 2015). Desde la independencia, el país fue incorporando al andamiaje legal ciertos avances en materia de derechos humanos hasta configurar el actual Estado nacional de derechos con una reciente Constitución, la de 2008, que "continuará profundizando, en consonancia con su antecesora de 1998 (Asamblea Nacional Constituyente, 1998), en el reconocimiento de los derechos colectivos de los pueblos y naciones" (Bretón, 2013).

El Buen Vivir es un modelo que se sustenta en el día a día, "es un camino que debe ser imaginado" (Acosta, 2015), por tanto "no puede quedar duda de que construirá una cadena de significados con un potencial transformador" Villalba (2013). Quizás tome mucho tiempo su implementación, por lo que de nada sirve que se encuentre como membrete en la papelería oficial o en los considerandos de las nuevas leyes, si en general la realidad y la práctica se confrontan impidiendo la generación de procesos horizontales como resultado de un real cambio de las sociedades en su conjunto, con ciudadanos que actúen en todos sus espacios identitarios y demanden pluralidad, armonía y vida plena.

El espacio público y toda su carga de significados es ideal para estos procesos de diálogo democrático e intercultural, para resignificar y mantener tradiciones y para el disfrute de las artes, la ciencia y la cultura (Carrasco-Bahamonde, 2011; Gurza, 2008: 44). Este, acompañado de nuevas matrices comunicacionales, debe ser el lugar ideal para avanzar en los debates acerca de la nueva epistemología del Sur (Herrera-Huérfano, SierraCaballero y Del Valle Rojas, 2016) entendida como el "reclamo" de los grupos tradicionalmente excluidos que demandan el reconocimiento de sus prácticas y la emergencia de "nuevos procesos 
de producción y de valoración de conocimientos válidos, científicos y no científicos, y de nuevas relaciones entre diferentes tipos de conocimiento" (De Sousa Santos, 2010: 43). Como lo plantea Ayala Mora (2011: 63), “el Buen Vivir o Sumak Kawsay no es solo una consigna, sino un camino alternativo para nuestras sociedades".

El ethos del Buen Vivir plantea cambios radicales, todo un desafío debido a la matriz de los latinoamericanos en general y ecuatorianos en particular, atravesados por centurias de colonialidad y colonialismo (Quijano, citado por Restrepo y Rojas: 91-114), la ideología del desarrollo, sus accidentes geográficos que definen sus principales marcadores culturales (Benites Vinueza, 2003; Hurtado, 2007: 177-225) y las dinámicas de la modernidad occidental. Por un lado es difícil encontrar la expresión de un "saber indígena puro" (Gudinas, 2011), por otro, está el conflicto permanente con los pueblos blanco y mestizo formados en la matriz colonial (Herrera-Huérfano, Sierra-Caballero y Del Valle Rojas, 2016; Sierra, 2016), lo mismo que las demandas del pueblo afrodescendiente que también acusa siglos de discriminación y explotación. Nuestros países están definidos por el colonialismo al que De Sousa Santos define como "una gramática social muy vasta que atraviesa la sociabilidad, el espacio público y el espacio privado, la cultura, las mentalidades y las subjetividades"; frente a ello propone un nuevo ecosistema de saberes al que se puede llegar mediante una traducción intercultural que permita entender y valorar las cosmovisiones no occidentales (2010: 29-33).

Un estudio de Calisto Friant y Langmore (2015), de la Universidad de Melbourne, señala que la filosofía del progreso colectivo y la armonía visionada entre y con la humanidad imaginada y la naturaleza, fundamentan una conciencia global que podrían impulsar la solidificación de los derechos de tercera generación. Por ello, Cubillo Guevara et al. (2016), a partir de la revisión de la literatura inherente, "para salir de los debates líricos y políticos" elaboran una síntesis en la que sistematizan un diagnóstico de la situación de América Latina, escenario en donde la propuesta del Buen Vivir se constituye en una alternativa al desarrollo con objetivos alcanzables desde el indigenismo, el socialismo o ecomarxismo y el posdesarrollismo (Figura 1).
La mayoría de trabajos coinciden en que el Buen Vivir es el paradigma alternativo al desarrollo moderno. Aquel, dice Merino, "visto como una alternativa a las teorías del desarrollo, puede como un concepto disruptivo a las teorías de desarrollo cuestionar los límites de nuestra imaginación política" (Merino, 2010) y, de una u otra manera, representa al Sur, vis-à-vis, frente a los debates del decrecimiento que propone el Norte (Beling et al., 2018). Asimismo, en otro trabajo, Vanhulst, y Beling (2014) destacan que, por un lado, denuncia la crisis del proyecto civilizatorio basado en la idea de un desarrollo ilimitado y, por otro, supera a los imperativos de la corriente de Desarrollo Sustentable. Es esta situación la que hace al Buen Vivir atractivo para una diversidad de intelectuales que están pensando en un modelo de organización social alternativo, menos antropocéntrico, que reduzca la presión sobre los limitados recursos del planeta.

Un estudio de Guardiola y García-Quero (2014) encontraron en diversas comunidades rurales de la región interandina de Ecuador niveles de satisfacción asociadas al espíritu del Buen Vivir (salud, familia, vida, comunidad, su ser individual, amigos, tiempo libre, sector donde vive), pese a las condiciones desfavorables en las que habitan, lo que se contradice con la visión extractivista y desarrollista de los gobiernos en turno. Se requiere, por tanto, políticas públicas en un "continuo proceso de acción reflexiva que garantice el respeto de los compromisos adoptados en la Constitución" (Gudynas, 2011).

En otra mirada externa acerca del proceso ecuatoriano Richard Lalander (2016), de la Universidad de Estocolmo, se pregunta si el desarrollo es una condición previa en el camino hacia una nueva forma de vida con bienestar social o si en el modelo del Sumak Kawsay es posible el desarrollo. La solución a estos problemas, remarca, no está en manos de los gobiernos, sino de las sociedades en su conjunto que tienen el reto de formar ciudadanos para dialogar en contextos de otredad, en una nueva matriz de interculturalidad "ingenio y creatividad" que se reproduce en varias experiencias andinas (Cañedo Argüelles, 2012) que permita construir un conocimiento que implique apertura a otras alternativas, otras posibilidades (Malik Liévano y Ballesteros Velázquez, 2015) que tienen como punto de partida el reconocimiento dentro y fuera de cada país de su 


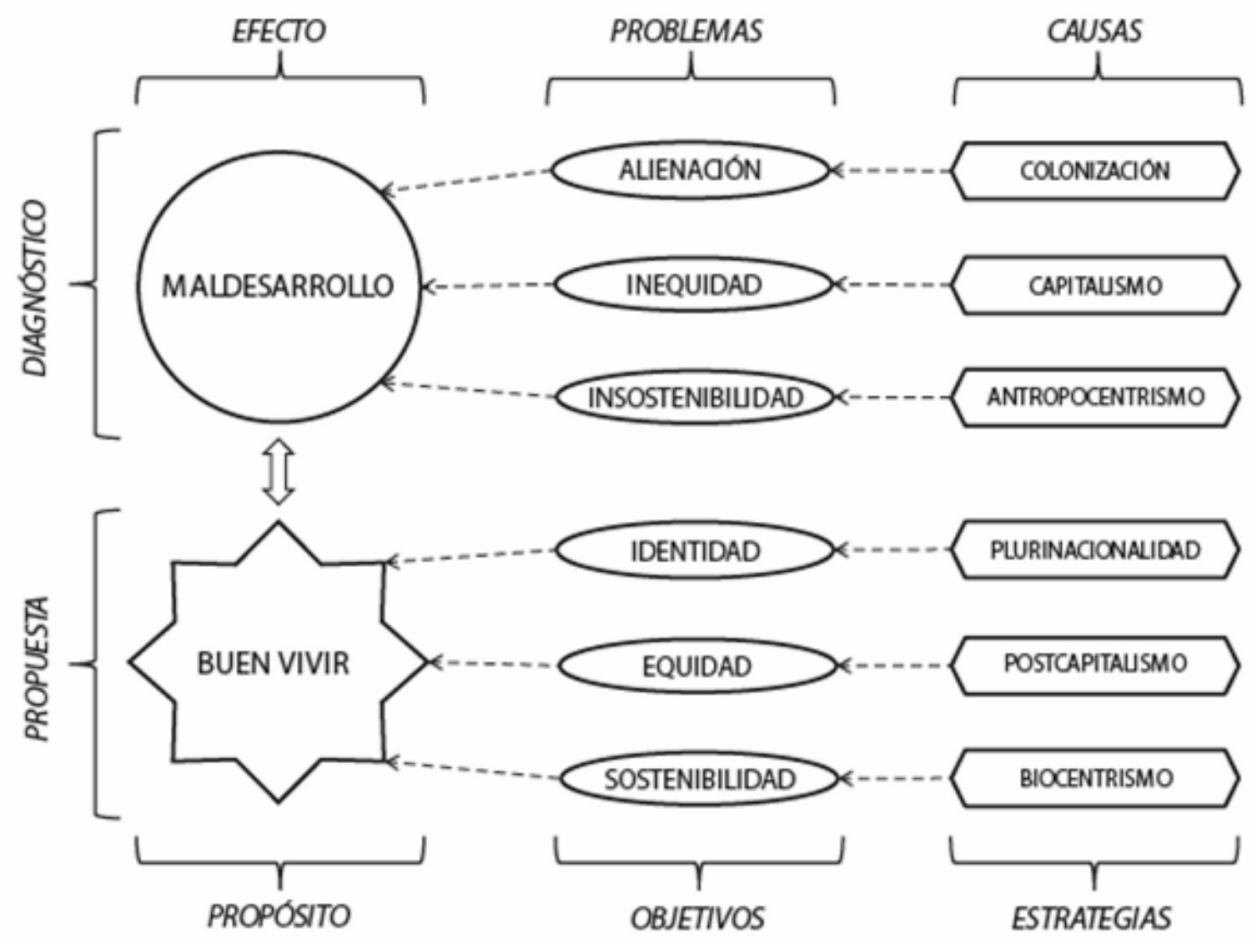

Figura 1. Fundamentos teóricos normativos del Buen Vivir.

Tomado de Cubillo Guevara et al. (2016).

condición de diverso, de multicultural (Johnson Mardones, 2015).

Michael Reid, editor de The Economist, en una entrevista en Letras Libres, enfatiza que la región necesita "una especie de socialdemocracia moderna que combine la democracia, el respeto por el estado de derecho, la justicia social y la redistribución sostenible, (aunque esto) es difícil en sociedades con tantos resentimientos, conflictos y desigualdades" (Gascón, 2018). Volviendo a Ecuador, como lo diría Benites Vinueza (2003), "es un pueblo que (...) anda en busca de su destino" (307).

El Buen Vivir y todo debate para construir una nueva epistemología van en camino a generar una nueva matriz de pensamiento del Sur Global, sin embargo estos nuevos discursos no penetran en el pueblo llano que sigue reproduciendo la matriz del racismo, la exclusión, la inferiorización. ¿Hay tiempo perdido?, tal vez no, sin embargo la situación política de la región, la corrupción y la confrontación permanente, afectan considerablemente a esta búsqueda nuevos convivires que refunden al Estado, al mercado y a sus ciudadanos.

\section{Conclusiones}

El Buen Vivir es un paradigma social en permanente resignificación. A la luz de los gobiernos progresistas latinoamericanos, la intelectualidad andina lo plantea como una alternativa a la ideología del desarrollo, sin embargo, las contradicciones del poder vaciaron sus contenidos con decisiones contrarias a su ethos caracterizado por la equidad, identidad y sustentabilidad. Aplicarlo es un desafío político, económico y cultural para los gobiernos de Ecuador y Bolivia que ataron sus constituciones al Buen Vivir, pese a que toda la estructura organizacional es atravesada por el desarrollo y la colonialidad que replican patrones históricos en las relaciones sociales. Aun así, el paradigma es parte de los debates para construir una nueva epistemología del sur que en su proceso de resignificación proponga un nuevo modelo de convivencia que pueda plantarle cara a las teorías del decrecimiento que plantea el norte. 


\section{Referencias Citadas}

Acosta, A.

2010 El Buen Vivir en el camino del post-desarrollo. Una lectura desde la Constitución de Montecristi. Quito, Ecuador: FES-ILDIS.

Acosta, A.

2015 El Buen Vivir como alternativa al desarrollo: Algunas reflexiones económicas y no tan económicas. Política y Sociedad, 52 (2), 299-330. http://dx.doi.org/10.5209/ rev_POSO.2015.v52.n2.45203

Acosta, A. y Cajas Guijarro, J.

201817 de marzo. Ecuador, un país incierto que no cambió. Sin permiso (5 marzo 2019). Recuperado de http://www.sinpermiso.info/textos/ ecuador-un-pais-incierto-que-no-cambio

Altman, P.

2013 El Sumak Kawsay en el discurso del movimiento indígena ecuatoriano. Indiana, 30, 283-299. Doi: http:// sci-hub.tw/10.18441/ind.v30i0.283-299.

Asamblea Nacional Constituyente

2008 Constitución de la República del Ecuador. Ciudad Alfaro.

Ayala, M.

2011 Interculturalidad, camino para el Ecuador. Quito, Ecuador: Fenocin, IESS, Universidad Andina Simón Bolívar.

Barranquero-Carretero, A., y Sáez-Baeza, C.

2015 Comunicación y Buen Vivir. La crítica descolonial y ecológica a la comunicación para el desarrollo y el cambio social. Palabra Clave, 18 (1), 41-82. doi: 10.5294/pacla.2015.18.1.3.

Beling, A. E.; Vanhulst, J.; Demaria, F.; Rabi, V.; Carballo, A. E., y Pelenc, J.

2018 Discursive Synergies for a "Great Transformation" Towards Sustainability: Pragmatic Contributions to a Necessary Dialogue Between Human Development, Degrowth, and Buen Vivir. Ecological Economics, 144, 304-313. Doi: 10.1016/j.ecolecon.2017.08.025.

Belotti, F.

2014 Entre bien común y Buen Vivir. Afinidades a distancia. Íconos. Revista de Ciencias Sociales (48), 41-54. Doi: https://doi.org/10.17141/iconos.48.2014.1208.

Benites Vinueza, L.

2003 Ecuador drama y paradoja. Quito: Campaña Nacional Eugenio Espejo por el libro y la lectura.

Bretón, V.

2013 Etnicidad, desarrollo y Buen Vivir, reflexiones críticas en perspectiva histórica. Revista Europea de Estudios Latinoamericanos y del Caribe. 95: 71-95. Doi: https:// doi.org/10.18352/erlacs.9231.

Cajas Guijarro, J.

201819 de julio. ¿Hacia dónde va el Ecuador de Lenin Moreno? Nueva Sociedad (5 de marzo 2019), https://nuso. org/articulo/hacia-donde-va-ecuador-lenin-moreno-/

Calisto Friant, M., y Langmore, J.

2015 The buen vivir: a policy to survive the Anthropocene? Global Policy, 6 (1), 64-71. Doi: 10.1111/1758-5899.12187.
Caria, S., y Domínguez, R.

2016 Ecuador's Buen vivir. Latin American Perspectives, 43 (1), 18-33. Doi: https://doi. org/10.1177/0094582X15611126

Cañedo-Argüelles, T.

2012 Diálogo cultural e intercambios como experiencia de Buen Vivir. La suma causai en Lima Norte. Diálogo Andino (40), 111-129. Recuperado de http://dialogoandino.cl/wp-content/uploads/2012/12/DA-40-2012-09.pdf

Carrasco Bahamonde, D.A.

2011 Espacio público y ciudadanía. Nuevos desafíos para la agenda de desarrollo en Chile. Polis, Revista Latinoamericana, 30, 1-18. Doi: http://dx.doi. org/10.4067/S0718-65682011000300002.

Carvalho, W. R., y Friggeri, F. P.

2015 Heterogeneidad estructural y Socialismo del Buen Vivir. Polis (40), 2-13. Recuperado de https://journals. openedition.org/polis/10633

Cubillo-Guevara, A. P., e Hidalgo-Capitán, A. L.

2015 El Sumak Kawsay genuino como fenómeno social amazónico ecuatoriano. OBETS. 10 (2), 301-333. Doi: https://doi.org/10.14198/OBETS2015.10.2.02.

Cubillo-Guevara, A. P., Hidalgo-Capitan, A. L., y Garcia-

Alvarez, S.

2016 Good Living as an alternative to development in Latin America. Iberoamerican Journal of Development Studies, 5 (2), 30-57.

Conaie (Confederación de Nacionalidades Indígenas de Ecuador)

2012 Proyecto político de la Conaie 1997. En Larco C. \& Espinoza L. (Comps.). El pensamiento político de los movimientos sociales (217-257). Quito, Ecuador: Ministerio Coordinador de la Política y Gobiernos autónomos Descentralizados de la República.

De la Cuadra, F.

2015 Buen Vivir: ¿Una auténtica alternativa post-capitalista? Polis (40), 2-10. Recuperado de https://journals. openedition.org/polis/10893.

De Sousa Santos, B.

2010 Refundación del Estado en América Latina, Perspectivas desde una epistemología del Sur. Lima: Instituto Internacional de Derecho y Sociedad y Programa Democracia y Transformación Global. Recuperado de http://www.boaventuradesousasantos.pt/ media/Refundacion\%20del\%20Estado_Lima2010.pdf

De Sousa Santos, B.

2014 ¿La Revolución ciudadana tiene quién la defienda? [Entrada de blog] (5 Junio 2018). Recuperado de http:// bit.ly/2le6F81

Fernández B.; Pardo L. y Salamanca, K.

2014 El Buen Vivir en el Ecuador. ¿Marketing político o proyecto en disputa? Un diálogo con Alberto Acosta. Íconos. 48, 101-117. Doi: https://doi.org/10.17141/ iconos.48.2014.1212.

García, S.

2014 Sumak kawsay o Buen Vivir como alternativa al desarrollo en Ecuador. Aplicación y resultados en el gobierno de Rafael Correa (2007-2011). (Tesis de doctorado). Universidad Complutense de Madrid, Madrid, España. 
Gascón, D.

20181 de diciembre. La izquierda latinoamericana cree que el anticapitalismo y la justicia social son mucho más importantes que las libertades y la democracia. Entrevista a Michael Reid. Letras Libres. 240. Recuperado de GTZ https://bit.ly/2GPxvla

2002 Cooperación con pueblo indígenas en América Latina. Taller, 28 al 30 de abril del 2002, Boquete, Panamá. S/l: Gesellschaft für Technische Zusammenarbeit (GTZ).

Guardiola, J., y García-Quero, F.

2014 Buen Vivir (living well) in Ecuador: Community and environmental satisfaction without household material prosperity? Ecological Economics, 107, 177-184. http:// dx.doi.org/10.1016/j.ecolecon.2014.07.032.

Gudynas, E.

2011 Buen Vivir: Germinando alternativas de desarrollo. Quito, Ecuador: ALAI. Descargado de http://bit. ly/211P4iq

Gudynas, E. y Acosta, A.

2011 "La Renovación de la crítica al desarrollo y el Buen Vivir como alternativa". Utopía y Praxis Latinoamericana 16 (53) 71-83. Recuperado de http://www.redalyc.org/articulo.oa?id=27919220007

Gurza Lavalle, A.

1998 Estado, sociedad y medios. Reivindicación de lo público. México: Plaza y Valdés Editores, Universidad Iberoamericana.

Herrera-Huérfano, E.; Sierra-Caballero, F., y Del Valle Rojas, C.

2016 Hacia una epistemología del sur. Decolonialidad del saber-poder informativo y nueva Comunicología Latinoamericana. Una lectura crítica de la mediación desde las culturas indígenas. Chasqui, 131, 77-105. Recuperado de https://revistachasqui.org/index.php/ chasqui/article/view/2694/2738

Hidalgo-Capitán, A., y Cubillo-Guevara, A.

2017 Deconstruction and Genealogy of Latin American Good Living (Buen Vivir): The (Triune) Good Living and Its Diverse Intellectual Wellsprings. En Carbonnier G., Campodónico H., \& Vázquez S. (Eds.), Alternative Pathways to Sustainable Development: Lessons from Latin America (pp. 23-50). Leiden; Boston: Brill. Recuperado de http://www.jstor.org/stable/10.1163/j. ctt1w76w3t.10

Hollender, R.

20128 de agosto. Política ambiental de los países "progresistas" en Latinoamérica: Buen Vivir vs. neo-extractivismo. ALAI (15 noviembre 2018). Recuperado de https://www.alainet.org/es/active/57062

Huanacuni, F.

2010 Buen Vivir/Vivir Bien Filosofía, políticas, estrategias y experiencias regionales andinas. Lima, Perú: Coordinadora Andina de Organizaciones Indígenas - CAOI.

Hurtado, O.

2007 Las costumbres de los ecuatorianos. Quito: Planeta.

J. Medina

201120 de enero. Suma qamaña, vivir bien y de vita beata. Una cartografía boliviana. [Mensaje en un blog]. (10 agosto 2018). Recuperado de http://lareciprocidad. blogspot.com/2011/01/suma-qamana-vivir-bien-y-de-vita-beata.html
Johnson Mardones, D.

2015 Formar ciudadanos interculturales en un mundo global: algunas notas desde los estudios curriculares. Diálogo Andino (13), 7-14. Doi: https://dx.doi. org/10.4067/S0719-26812015000200002.

Lalander, R. y Merimaa, M.

2018 The Discursive Paradox of Environmental Conflict: Between Ecologism and Economism in Ecuador. Foro de Estudios para el Desarrollo, 45 (3), 485-511. doi: https:// doi.org/10.1080/08039410.2018.1427622.

Lalander, R.

2016 The Ecuadorian resource dilemma: Sumak Kawsay or development? Critical Sociology, 42 (4-5), 623-642. doi: https://doi.org/10.1177/0896920514557959.

Larrea Maldonado, A.M.

2012 Modo de Desarrollo, Organización Territorial y Cambio Constituyente en Ecuador. Quito, Ecuador: Senplades.

Malik Liévano, B. y Ballesteros Velázquez, B.

2015 La construcción del conocimiento desde el enfoque intercultural. Diálogo Andino (47), 15-25. Doi: http:// dx.doi.org/10.4067/S0719-26812015000200003

Manosalvas, $\mathrm{M}$.

2014 Buen Vivir o sumak kawsay. En busca de nuevos referenciales para la acción pública en Ecuador. Íconos. Revista de Ciencias Sociales (49), 101-121. Doi: https:// doi.org/10.17141/iconos.49.2014.1273.

Margolis Schweber, E.

2017 El buen vivir: La búsqueda de su comprensión a través de diferentes filosofías. Estudios Políticos, 40, 123-147. Doi: https://doi.org/10.1016/j.espol.2017.03.003

Merino, $\mathrm{R}$

2016 An alternative to 'alternative development'?: Buen vivir and human development in Andean countries. Oxford Development Studies, 44 (3), 271-286. http:// dx.doi.org/10.1080/13600818.2016.1144733.

Oviedo, A. (Fides Televisión)

20126 de junio. Entrevista a Atawallpa Ovideo para El Hombre invisible. Descargado de: https://www.youtube. com/watch?v=XPKT9evokhk

Ramírez, R.

2012 Socialismo del sumak kausay o biosocialismo republicano. Quito: Senescyt.

Ramírez, R.

20146 de febrero. La transición ecuatoriana hacia el Buen Vivir. [Entrada de blog]. (20 agosto 2018). Descargado de: http://reneramirez.ec/la-transicion -ecuatoriana-hacia-el-buen-vivir/

Restrepo, E. y Rojas, A.

2010 Inflexión decolonial: fuentes, categorías y cuestionamientos. Popayán: Editorial Universidad del Cauca.

Salamea Córdova, M.

2014 Una revolución sin ciudadanía. En Cuvi Juan (Ed.), La restauración conservadora del correísmo (pp. 18-29). Quito: Montecristi Vive.

Satrustegui, K.

2013 Decrecimiento y Buen Vivir ¿paradigmas convergentes? Debates sobre el postdesarrollo en Europa y América Latina. Revista de Economía Mundial, (35), 197-216. Recuperado de http://www.sem-wes.org/sites/default/ files/revistas/rem35_11.pdf 
Senplades (Secretaría Nacional de Planificación y Desarrollo) 2009 Plan Nacional para el Buen Vivir 2009-2013: Construyendo un Estado Plurinacional e Intercultural. Quito: Senplades.

Senplades

2013. Plan Nacional para el Buen Vivir 2013-2017: Quito: Senplades.

Senplades

2017 Plan Nacional de Desarrollo 2017-2021: Quito: Senplades.

Shade, L.

2015 Sustainable development or sacrifice zone? Politics below the surface in post-neoliberal Ecuador. The Extractive Industries and Society, 2 (4), 775-784. https:// doi.org/10.1016/j.exis.2015.07.004.

Sierra Caballero, F.

2016 Comunicación y Buen Vivir. Nuevas matrices teóricas del pensamiento latinoamericano. Chasqui, 0 (131), 09-18. Recuperado de http://www.revistachasqui.org/ index.php/chasqui/article/view/2899.

Turra Díaz, O.; Lagos Pando, M., y Valdés Vera, M.

2018 Identidad cultural indígena en el discurso pedagógico de la historia. Una mirada al currículum latinoamericano. Diálogo Andino (57), 49-60. Doi: http:// dx.doi.org/10.4067/S0719-26812018000300049.

Ugarteche, $\mathrm{O}$.

2018 Los gobiernos progresistas de América Latina en el contexto internacional: una aproximación a sus límites.
Discursos del Sur, revista de teoría crítica en Ciencias Sociales, 0 (2), 33-66. Doi: http://dx.doi.org/10.15381/ dds.v0i2.15477.

Vanhulst, J., y Beling, A. E.

2014 Buen vivir: Emergent discourse within or beyond sustainable development? Ecological Economics, 101, 54-63. doi: 10.1016/j.ecolecon.2014.02.017

Vanhulst, J.

2015 El laberinto de los discursos del Buen Vivir: entre Sumak Kawsay y Socialismo del siglo XXI. Polis (07176554), (40), 2-21. Recuperado de https://journals. openedition.org/polis/10727.

Villalba, U.

2013 Buen Vivir vs Development: a paradigm shift in the Andes? Third World Quarterly, 34 (8), 1427-1442. Doi: 10.1080/01436597.2013.831594.

Villalba-Eguiluz, CU, y Etxano, I.

2017 Buen Vivir vs Desarrollo (II): Los límites del (neo) extractivismo. Economía ecológica, 138, 1-11. Doi: 10.1016/j.ecolecon.2017.03.010.

Viteri Gualinga, C.

2002 Visión indígena del desarrollo en la Amazonía. Polis. Revista Latinoamericana (3). Descargado de http://polis. revues.org/7678.

Walsh, C.

2010 Development as Buen Vivir: Institutional arrangements and (de) colonial entanglements. Development, 53 (1), 15-21. Doi: 10.1057/dev.2009.93.

Notas

El nombre originario de la América prehispánica.

Se privilegió el idioma original de la cita porque recoge de mejor manera el espíritu de la reflexión. Se ofrece una traducción: "armonía con la naturaleza, respeto por los valores y principios de los pueblos indígenas; satisfacción de las necesidades básicas; justicia social y equidad como responsabilidades del Estado y la democracia".

3 Este es el nombre que el gobierno de Rafael Correa le dio a su gobierno.

4 Para salir al paso a las críticas, Senplades ha revisado su fundamentación inicial acerca del Buen Vivir y publica en su Plan Nacional 2013-2017 que el Sumak Kawsay fortalece la cohesión social, los valores comunitarios y la participación activa de individuos y colectividades en las decisiones relevantes, para la construcción de su propio destino y felicidad. Se fundamenta en la equidad con respeto a la diversidad, cuya realización plena no puede exceder los límites de los ecosistemas que la han originado. No se trata de volver a un pasado idealizado, sino de encarar los problemas de las sociedades contemporáneas con responsabilidad histórica. El propósito del Socialismo del Buen Vivir es defender y fortalecer la sociedad, el trabajo y la vida en todas sus formas. El primer paso es resolver el acceso a bienes, oportunidades y condiciones que garanticen -al individuo, a la colectividad y a las generaciones futuras- una vida digna sin perjudicar a la naturaleza. El Buen Vivir es una práctica diaria.

5 Al remarcar el histórico efecto de las luchas sociales, Carvalho y Friggeri (2015) señalan: “(...) la propuesta más clara construida desde nuestra región que configura un horizonte postcapitalista y que cuenta con la ventaja de no ser solamente una idea teórica o una utopía lejana, sino de ser algo que tiene siglos de construcción en nuestra región y que, con innumerables heridas, sigue viva en muchísimas comunidades, fundamentalmente indígenas y campesinas". 
